Article

\title{
Novel Repositioning Therapy for Drug-Resistant Glioblastoma: In Vivo Validation Study of Clindamycin Treatment Targeting the mTOR Pathway and Combination Therapy with Temozolomide
}

Takeyoshi Eda ${ }^{1}$, Masayasu Okada ${ }^{2} \mathbb{D}$, Ryosuke Ogura ${ }^{2}$, Yoshihiro Tsukamoto ${ }^{2}$, Yu Kanemaru ${ }^{2}$, Jun Watanabe ${ }^{2} \mathbb{D}$, Jotaro On ${ }^{2}\left(\mathbb{D}\right.$, Hiroshi Aoki ${ }^{2}$, Makoto Oishi ${ }^{2}$, Nobuyuki Takei ${ }^{3} \mathbb{D}$, Yukihiko Fujii ${ }^{2}$ and Manabu Natsumeda ${ }^{2,3, *(D)}$

1 Division of Pharmacy, Medical and Dental Hospital, Niigata University, Niigata 951-8520, Japan; eda@med.niigata-u.ac.jp

2 Department of Neurosurgery, Brain Research Institute, Niigata University, Niigata 951-8585, Japan; masayasu_okd@bri.niigata-u.ac.jp (M.O.); oguryou@bri.niigata-u.ac.jp (R.O.); yoshi.tsukamoto@me.com (Y.T.); yu.k93@bri.niigata-u.ac.jp (Y.K.); watanabejun1003@yahoo.co.jp (J.W.); jotaro-on_silver@sky.hi-ho.ne.jp (J.O.); aoki1123@yahoo.co.jp (H.A.); mac.oishi@mac.com (M.O.); yfujii@bri.niigata-u.ac.jp (Y.F.)

3 Department of Brain Tumor Biology, Brain Research Institute, Niigata University, Niigata 951-8585, Japan; nobtak0615@gmail.com

* Correspondence: natsumeda@bri.niigata-u.ac.jp

check for updates

Citation: Eda, T.; Okada, M.; Ogura, R.; Tsukamoto, Y.; Kanemaru, Y.; Watanabe, J.; On, J.; Aoki, H.; Oishi, M.; Takei, N.; et al. Novel Repositioning Therapy for Drug-Resistant Glioblastoma: In Vivo Validation Study of Clindamycin Treatment Targeting the mTOR Pathway and Combination Therapy with Temozolomide. Cancers 2022, 14 , 770. https://doi.org/10.3390/ cancers14030770

Academic Editor: Carlos M. Telleria

Received: 22 December 2021

Accepted: 30 January 2022

Published: 2 February 2022

Publisher's Note: MDPI stays neutral with regard to jurisdictional claims in published maps and institutional affiliations.

Copyright: (C) 2022 by the authors. Licensee MDPI, Basel, Switzerland. This article is an open access article distributed under the terms and conditions of the Creative Commons Attribution (CC BY) license (https:// creativecommons.org/licenses/by/ $4.0 /)$.
Simple Summary: Given the significant costs and lengthy timelines of drug development and clinical trials, drug repositioning is a promising alternative to find effective treatments for brain tumors quickly and inexpensively. In the present study, using a simple drug screen of macrolides, we found that clindamycin (CLD) had cytotoxic effects on glioblastoma (GBM) cells. Further studies showed the inhibition of the mammalian target of rapamycin (mTOR) pathway as the key mechanism of action. Interestingly, we found that co-treatment with temozolomide (TMZ), the alkylating agent considered as standard therapy in GBM, enhanced these effects and proposed the inhibition of O6-methylguanine-DNA methyltransferase (MGMT) protein by CLD as a potential mechanism for this combination effect.

Abstract: Multimodal therapy including surgery, radiation treatment, and temozolomide (TMZ) is performed on glioblastoma (GBM). However, the prognosis is still poor and there is an urgent need to develop effective treatments to improve survival. Molecular biological analysis was conducted to examine the signal activation patterns in GBM specimens and remains an open problem. Advanced macrolides, such as azithromycin, reduce the phosphorylation of p70 ribosomal protein S6 kinase (p70S6K), a downstream mammalian target of rapamycin (mTOR) effector, and suppress the proliferation of T-cells. We focused on its unique profile and screened for the antitumor activity of approved macrolide antibiotics. Clindamycin (CLD) reduced the viability of GBM cells in vitro. We assessed the effects of the candidate macrolide on the mTOR pathway through Western blotting. CLD attenuated p70S6K phosphorylation in a dose-dependent manner. These effects on GBM cells were enhanced by co-treatment with TMZ. Furthermore, CLD inhibited the expression of the O6-methylguanine-DNA methyltransferase (MGMT) protein in cultured cells. In the mouse xenograft model, CLD and TMZ co-administration significantly suppressed the tumor growth and markedly decreased the number of Ki-67 (clone MIB-1)-positive cells within the tumor. These results suggest that CLD suppressed GBM cell growth by inhibiting mTOR signaling. Moreover, CLD and TMZ showed promising synergistic antitumor activity.

Keywords: glioblastoma; signal transduction; xenograft model; drug repositioning 


\section{Introduction}

Glioblastoma (GBM) accounts for the majority of primary brain tumors and is considered as a grade IV glioma based on the WHO classification system [1]. The median survival of patients with GBM is approximately 15 months [2,3]. Despite the development of multimodal therapy with surgical resection, radiation, and temozolomide (TMZ)-based chemotherapy, GBM prognosis remains poor. GBM is characterized by diverse genetic and epigenetic alterations, such as isocitrate dehydrogenase (IDH) 1/2 mutations, O6methylguanine-DNA methyltransferase (MGMT) promoter methylation, epidermal growth factor receptor (EGFR) amplification, and EGFR variant III (EGFRvIII) expression [4-7]. In particular, EGFR amplification, PTEN mutations, CDKN2A deficiency, and TP53 gene mutations were investigated to establish the association between genetic alterations and GBM prognosis [8]. Comprehensive genomic analysis revealed aberrant signal transduction through various pathways, including the receptor tyrosine kinase (RTK)-Rasphosphoinositide 3-kinase (PI3K) pathway, Rb pathway, and p53 pathway $[9,10]$. These studies suggest that genetic alterations or RTK-Ras-PI3K, Rb, and p53 pathways act cooperatively and contribute to the proliferation and maintenance of GBM cells [11]. Further studies are required to better understand the GBM etiology and to develop novel molecular targeted strategies.

Macrolide antibiotics (macrolides) act on Gram-positive bacteria by reversibly binding to the bacterial 505 ribosomal subunit and inhibiting peptide elongation. Accumulating evidence showed that macrolides have immunomodulatory properties in vitro [12]. Macrolides exhibit atypical pharmacological profiles and inhibit the synthesis and secretion of pro-inflammatory cytokines, including tumor necrosis factor (TNF)-alpha, interleukin (IL)-1, IL-6, and IL-8 [13,14]. Long-term or low-dose administration of macrolides reduces the symptoms of diffuse panbronchiolitis [15]. A previous study showed that cell proliferation and cytokine secretion by CD4+ T-cells were inhibited by azithromycin treatment [16] In addition, azithromycin suppressed mammalian target of rapamycin (mTOR), which is frequently activated in cancer cells [16-19].

Herein, we focused on the atypical features of macrolides and examined the possibility of applying these drugs to conventional chemotherapy for GBM. During our primary assessment, we investigated the effects of various macrolide compounds, namely, azithromycin, clarithromycin, clindamycin (CLD), and erythromycin, on the growth and survival of human GBM cell lines and found that CLD remarkably suppressed GBM cell proliferation. However, our understanding of the molecular mechanism underlying CLD-mediated cytotoxicity is incomplete. We hypothesized that the mTOR signaling pathway might be a potential target of CLD. To verify this, we investigated the effects of CLD on growth and survival in several GBM cell lines and explored the specific molecular targets of CLD with a focus on p70S6K, a substrate of mTOR. We further tested the efficacy of CLD in vivo, either alone or in combination with TMZ, using the mouse xenograft model.

\section{Materials and Methods}

\subsection{Reagents}

For the in vitro assays, TMZ (TEMODAR capsules; MSD, Japan) and clindamycin hydrochloride (Dalacin capsules; Pfizer, Japan) were used. TMZ was dissolved in dimethyl sulfoxide (DMSO) and stored at $-20^{\circ} \mathrm{C}$ after preparing a $100 \mathrm{mM}$ stock solution. CLD was dissolved in sterile water to produce a $330 \mathrm{mM}$ stock solution and stored at $-20^{\circ} \mathrm{C}$. For the in vivo treatment, TMZ (TEMODAR injection; MSD, Tokyo, Japan) and CLD (clindamycin phosphate; Dalacin S injection; Pfizer, Tokyo, Japan) were administered to the animals after diluting them in an appropriate solvent.

\subsection{Cell Culture}

Cells were grown in DMEM containing 10\% fetal bovine serum (Sigma-Aldrich, St. Louis, MO, USA). Human glioblastoma cell lines (U251, T98G, and LN229) were obtained from the American Type Culture Collection (ATCC). NGT41 is a cell line established from 
a disseminated lesion of the cervical spinal cord from a BRAF V600E-mutant epithelioid glioblastoma patient and cultured as previously reported [20].

\subsection{Cell Viability Assays}

The cytotoxic effects of TMZ and CLD were determined by using the cell viability assay reagent WST-1 (Takara Bio, Japan), as described previously [21]. Briefly, glioma cells were seeded at the density of 1-1.5 $\times 10^{3}$ cells/well in 96-well flat-bottomed plates and incubated at $37^{\circ} \mathrm{C}$ overnight. Afterward, the cells were treated with TMZ $(0,62.5,125$, 250 , or $500 \mu \mathrm{M})$ or $\operatorname{CLD}(0,110,220,440$, or $660 \mu \mathrm{M})$ for $72 \mathrm{~h}$. Following treatment, WST-1 reagent $(10 \mu \mathrm{L})$ was added to each well and incubated for $1-2 \mathrm{~h}$ at $37^{\circ} \mathrm{C}$. Absorbance was measured at $450 \mathrm{~nm}$ using a microplate reader. The viability of untreated cells was considered as $100 \%$.

\subsection{Western Blotting}

Cells or tumor tissues were lysed and sonicated in lysis buffer $(50 \mathrm{mM}$ Tris- $\mathrm{HCl}$, $\mathrm{pH}$ 7.5, $150 \mathrm{mM} \mathrm{NaCl}, 2 \%$ sodium dodecyl sulfate (SDS), $10 \mathrm{mM} \mathrm{NaF}, 2 \mathrm{mM} \mathrm{Na} \mathrm{VO}_{4}$, $5 \mathrm{mM}$ EDTA $1 \mathrm{mM}$ phenylmethylsulfonyl fluoride) and CompleteTM Protease inhibitor cocktail (Roche, Indianapolis, IN, USA). The lysates were centrifuged and the supernatant was collected. The protein concentration in the lysates was determined using the Micro BCA Protein assay kit (Thermo Fisher Scientific, Rockford, MI, USA). Equal amounts of protein $(15-30 \mu \mathrm{g})$ were subjected to SDS-polyacrylamide gel electrophoresis (PAGE) and transferred to a nitrocellulose membrane. Western blotting was performed using antiphospho-p70S6K (Thr389) (1:500), anti-phospho-S6 (Ser240/244) (1:1000), anti-S6 (1:4000), anti-phospho-4EBP1 (Thr37/46) (1:1000), and anti- $\beta$-actin (1:4000) polyclonal antibodies (Cell Signaling Technologies, Danvers, MA, USA). Anti-p70S6K antibody was purchased from Santa Cruz Biotechnology (Santa Cruz, CA, USA). Membranes were incubated with the indicated primary antibodies at $4{ }^{\circ} \mathrm{C}$ overnight. After the membranes were rinsed with TBST (50 mM Tris- $\mathrm{HCl} \mathrm{pH} 7.5$ and $150 \mathrm{mM} \mathrm{NaCl}$ containing $0.1 \%$ Tween 20) and subsequently incubated with horseradish-peroxidase-conjugated secondary antibodies (1:10000; Santa Cruz CA, USA). Immunoreactivity was detected via the chemiluminescence detection method using the ECL system (Bio-Rad, Hercules, CA, USA). The immunoreactive bands were visualized using GeneGnome (Syngene, Cambridge, UK) and quantified using Genetools software (Syngene). The dose dependence of CLD on p70S6K phosphorylation at Thr389 was examined in cultured cells after $72 \mathrm{~h}$ of treatment. The levels of phosphorylated and total p70S6K were analyzed via Western blotting and quantified using the Syngene Bio Imaging system (Syngene, Cambridge, UK). The phospho/total p70S6K ratio was determined. $\beta$-actin was used as the loading control. For the original Western blots, see the Figure S6.

\subsection{In Vitro mTOR Kinase Assays}

The immunoprecipitation and kinase assays were performed as described previously [22,23]. Briefly, cells were lysed in ice-cold buffer A (50 mM Tris- $\mathrm{HCl} \mathrm{pH} \mathrm{8.0,150} \mathrm{mM}$ $\mathrm{NaCl}, 1 \mathrm{mM}$ EGTA, $5 \mathrm{mM}$ EDTA, $20 \mathrm{mM}$ glycerophosphate, $0.5 \mathrm{mM}$ dithiothreitol, CompleteTM, and PhosStopTM phosphatase inhibitor cocktails (Roche, San Francisco, CA, USA)). The supernatants from the centrifuged samples were incubated with Protein G SepharoseTM (GE Healthcare, Chicago, IL, USA), coupled with anti-mTOR (N5D11) antibody (IBL, Fujioka, Japan) for $2 \mathrm{~h}$ at $4{ }^{\circ} \mathrm{C}$. The immunocomplex was washed and the kinase assay was initiated by adding the reaction buffer (10 mM HEPES, $50 \mathrm{mM}$ glycerophosphate, $50 \mathrm{mM} \mathrm{NaCl}, 10 \mathrm{mM} \mathrm{MgCl} 2,4 \mathrm{mM} \mathrm{MnCl} 2,250 \mu \mathrm{M}$ ATP, and recombinant GST-4EBP1 $(1 \mu \mathrm{g} /$ sample) $)$. After incubation for $20 \mathrm{~min}$ at $30^{\circ} \mathrm{C}$, the reaction was terminated by adding the SDS sample buffer. The samples were boiled and subjected to SDS-PAGE. Western blotting was performed with anti-phospho-4EBP1 (Thr37/46) antibody to detect the mTOR complex (mTORC) 1 activity. 


\subsection{Cell Cycle Analysis}

Tumor cells treated with CLD $(440 \mu \mathrm{M})$ for $24 \mathrm{~h}$ were trypsinized and washed with PBS. At least $1 \times 10^{5}$ cells were fixed with ice-cold $70 \%$ ethanol at $4{ }^{\circ} \mathrm{C}$. The cells were collected via centrifugation and stained with propidium iodide (PI) using the MUSE cell cycle reagents (Millipore, Billerica, MA, USA) following the manufacturer's instructions, as described previously [24].

\subsection{Experimental Animals}

Four-week-old male nude mice (BALB/C-nu/nu, Charles River Laboratories Inc., Yokohama Japan) were used for the in vivo experiments. Mice were housed under aseptic conditions in a plastic cage and provided free access to food and water. Each cage was kept in a colony room $\left(22 \pm 1.0^{\circ} \mathrm{C}\right)$ under a $12 \mathrm{~h}$ light-dark cycle. All of the animal experiments described here were approved by the Animal Committee of Niigata University (No. SA00519) and were performed in accordance with the Guiding Principles for the Care and Use of Laboratory Animals (NIH, Bethesda, MD, USA).

\subsection{Establishment of a Patient-Derived Xenograft Model}

For the subcutaneous tumor model, NGT41 cells were suspended in Neurobasal Medium (Life Technologies Corporation, Carlsbad, NY, USA) and implanted subcutaneously $\left(1 \times 10^{6}\right.$ cells per place $)$ into the nude mice as described previously [20]. When the tumor volume reached $50 \mathrm{~mm}^{3}$, the mice were randomly divided into four groups. Mice were treated daily with solvent (vehicle control), TMZ (5 mg/kg), CLD (400 mg/kg), and TMZ (5 mg/kg) + CLD (400 mg/kg) via intraperitoneal injection for 10 days. The tumor size was measured daily with calipers, and tumor volume was calculated using the formula: tumor volume $\left(\mathrm{mm}^{3}\right)=$ [length $(\mathrm{mm}) \times$ width $\left.\left(\mathrm{mm}^{2}\right)\right] / 2$ [25].

\subsection{Histopathological Examination}

Mice were deeply anesthetized with medetomidine hydrochloride $(0.3 \mathrm{mg} / \mathrm{kg})$, midazolam $(4 \mathrm{mg} / \mathrm{kg})$, and butorphanol tartrate $(5 \mathrm{mg} / \mathrm{kg})$ via intraperitoneal injection, and tumors were resected. The tumors were fixed with $4 \%$ neutral-buffered paraformaldehyde, dehydrated using $70 \%$ ethanol, and embedded in paraffin wax. Sections (3 $\mu \mathrm{m}$ thick) were cut from the paraffin blocks, and immunostaining was performed as described previously [26]. Sections were stained with 3,3'-diamonobenzidine as a chromogen and counterstained with hematoxylin solution (Wako Chemicals Inc., Osaka, Japan), and then processed for the HE staining and immunostaining. The following mouse monoclonal antibodies were used: anti-Ki-67 monoclonal antibody (clone MIB-1; 1:100; Biogenex, Fremont, CA, USA) and anti-MGMT monoclonal antibody (clone MT3.1; 1:50; Chemicon International, Temecula, CA, USA; 1:50), MGMT immunoreactivity was evaluated in representative areas of the tumors showing the characteristic features [27].

\subsection{Statistical Analyses}

Data were expressed as mean \pm SE and were subjected to parametric analyses. When univariate data with more than two groups showed a similar distribution, we used the analysis of variance (ANOVA) to assess the statistical differences in terms of time, dose, and experimental groups, followed by Bonferroni's post hoc test for multiple comparisons. Alternatively, Student's $t$-test (two-tailed) was used for univariate data analysis of two groups. All statistical analyses were performed using the GraphPad Prism 6 software (GraphPad Software, San Diego, CA, USA).

\section{Results}

\subsection{Antiproliferative Activity of Clindamycin in Cultured Glioblastoma Cells}

Macrolides are known to regulate inflammation and immune responses. We investigated the effects of approved macrolides on cell growth using human GBM cell lines. In our preliminary experiments, we treated U251 and T98G cells with azithromycin, clar- 
ithromycin, clindamycin (CLD), and erythromycin. The results showed that CLD inhibited the growth and survival of the U251 and T98G cells (Figure S1). Moreover, CLD also inhibited the growth of the U251, T98G, LN229, and NGT41 cell lines (Figure 1A-D). The inhibitory effect of CLD on these cells was dose-dependent. The minimal dose of CLD used to reach a 50\% inhibitory effect was observed at 440-660 $\mu \mathrm{M}(\mathrm{U} 251,440 \mu \mathrm{M}$; T98G, $500 \mu \mathrm{M}$; LN229, $660 \mu \mathrm{M}$; and NGT41, $500 \mu \mathrm{M})$. Thus, a dosage of $440 \mu \mathrm{M}$ was used for subsequent experiments. These results suggested that CLD suppressed the growth of malignant glioma cells in vitro.
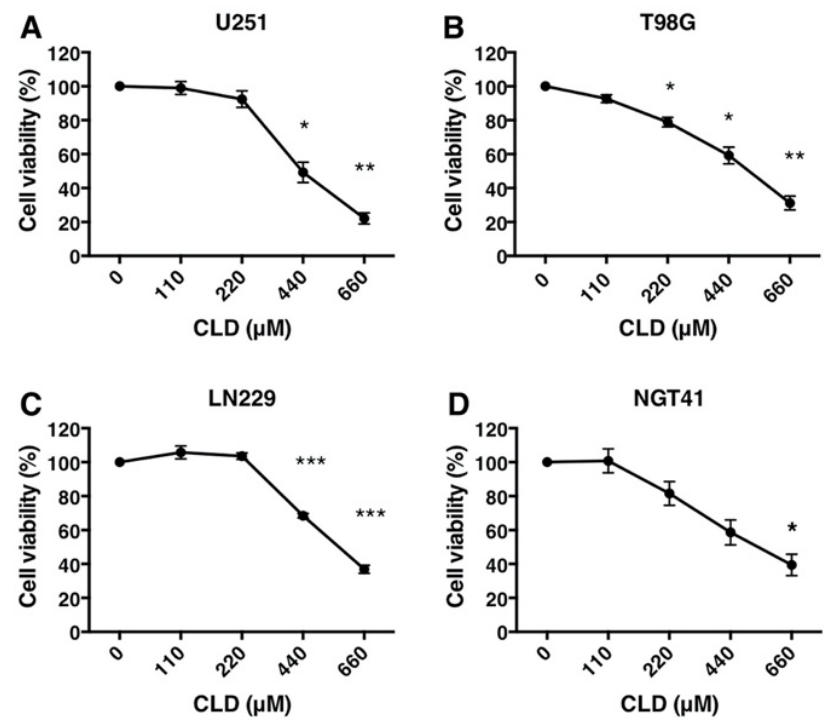

Figure 1. Cytotoxic effects of clindamycin on cultured glioblastoma cell lines. Dose responses of clindamycin (CLD) on cell viability in glioblastoma cell lines (A-D). Cells were treated with CLD $(0,110,220,440$, or $660 \mu \mathrm{M})$ for $72 \mathrm{~h}$ and subjected to a WST-1 cell viability assay. The viability of untreated cells (vehicle control: $0 \mu \mathrm{M}$ CLD) was considered $100 \%$. Data are presented as the mean \pm SE. Similar results were obtained from triplicate experiments $\left({ }^{*} p<0.05,{ }^{* *} p<0.01\right.$, and *** $p<0.001$ vs. control culture: one-way ANOVA).

\subsection{Effects of Clindamycin on mTOR Signaling in Glioblastoma Cell Lines}

To investigate the effects of the CLD on mTOR signaling, we examined p70S6K phosphorylation via Western blotting using the anti-phospho p70S6K (Thr389) antibody. Results showed that CLD treatment reduced the p70S6K phosphorylation in a dose-dependent (Figure 2A,C,E,G) and time-dependent manner (Figure 3A-H). CLD also inhibited the phosphorylation of ribosomal S6 protein (S6), a substrate of $\mathrm{p} 70 \mathrm{~S} 6 \mathrm{~K}$, in a dose-dependent manner (Figure 2B,D,F,H), indicating that CLD inhibited the phosphorylation of p70S6K and $\mathrm{S} 6$ proteins in a dose-dependent manner. 
A

T98G

P.p70s6K (Thr389) $\ldots \ldots \ldots$

p70s6K

ß-actin

CLD ( $\mu 1 A)$
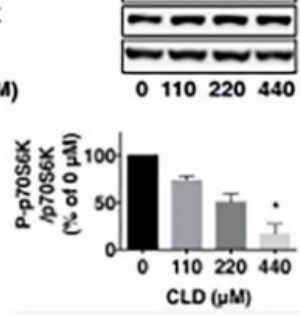

E

U251

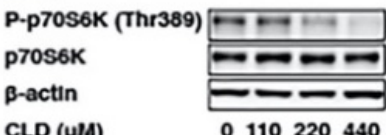

CLD ( $\mu / A)$

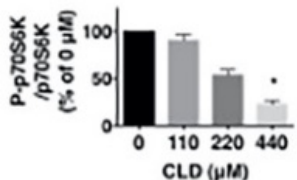

B

T98G

P-S6 (Ser240/244)

S6

p-actin

CLD ( $\mu M)$

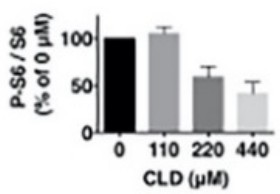

F

U251

P.S6 (Ser240/244) $-\infty-$

s6

B-actin

CLD ( $\mu M)$

0110220440
C

NGT41

P-p70S6K (Thr389) -

p70s6K

B-actin

CLD ( $(\mu / A)$

G

LN229

P.p70S6K (Thr389) - - - -

p70s6K

B-actin

CLD ( $\mu / A)$

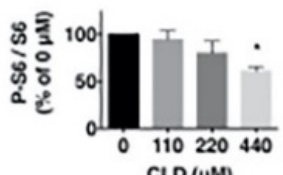

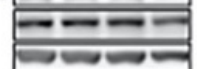

0110220440
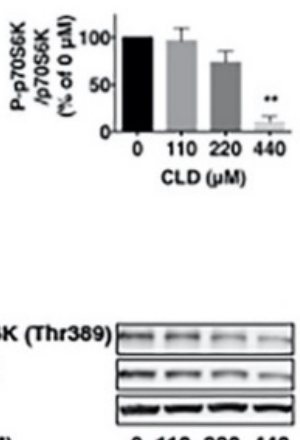

D

NGT41

P.S6 (Ser240/244)

S6

阝-actin

CLD ( $\mu M)$

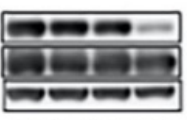

0110220440

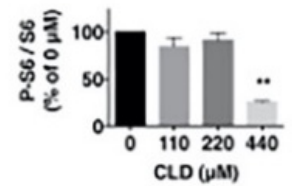

H

LN229

P-S6 (Ser240/244) C D

s6

ß-actin

CLD ( $\mu M)$
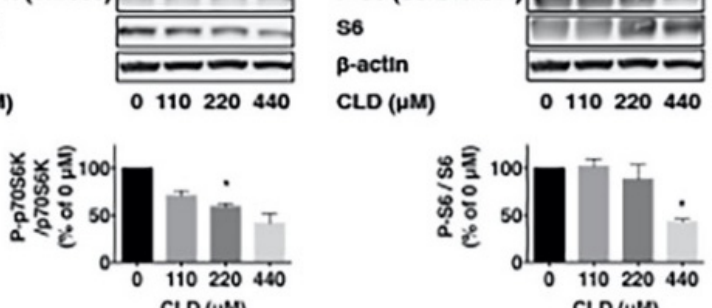

0110220440

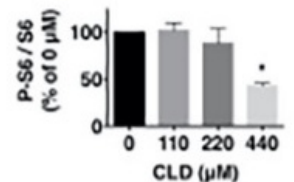

Figure 2. Effect of clindamycin on the phosphorylation of p70S6K and S6 in glioblastoma cell lines. Dose responses of clindamycin (CLD) on the phosphorylation of p70S6K at Thr389 and S6 at Ser240/Ser244 in glioblastoma cell lines. Cells were treated with CLD $(0,110,220$, or $440 \mu \mathrm{M})$ for $72 \mathrm{~h}$ and subjected to Western blotting. The levels of phosphorylated and total p70S6K were indicated at the corresponding bands (A,C,E,G). Western blotting analysis was subjected to densitometric quantification after standardizing the ratio of phospho/total p70S6K (below panel). The phosphorylation and total S6 levels in glioblastoma cell lines were similarly analyzed via Western blotting (B,D,F,H). $\beta$-actin was used as the internal control level in all cases. Data are shown as the mean $\pm \mathrm{SE}$, similar results shown were representative of three independent experiments. Each group was compared to the 0 concentration level to determine statistical significance. $\left({ }^{*} p<0.05\right.$ and ${ }^{* *} p<0.01 \mathrm{vs}$. control culture: one-way ANOVA).

\subsection{Direct Effect of Clindamycin on mTOR Kinase Activity}

To verify the inhibitory effect of CLD on mTOR signaling, we measured the mTOR kinase activity in vitro. Cells were treated with CLD $(440 \mu \mathrm{M})$ for $72 \mathrm{~h}$ and then lysed to collect the protein. Equal amounts of protein from treated or untreated cells were subjected to immunoprecipitation with anti-mTOR antibody (N5D11). Using recombinant GST-4EBP1 as a substrate, the kinase activity of mTORC1 was evaluated. The results showed that CLDtreated cells had lower mTOR kinase activity compared to untreated cells (Figure 4A,B), suggesting that CLD directly inactivated mTOR signaling in GBM cells. 


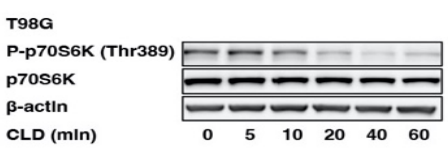

C

NGT41

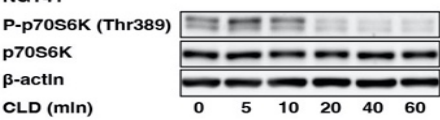

CLD (mIn)

E

U251

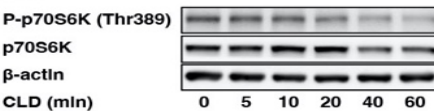

CLD (mIn)

G

LN229

P-p70S6K (Thr389) -

p70s6K

$\beta$-actin

CLD (mIn)

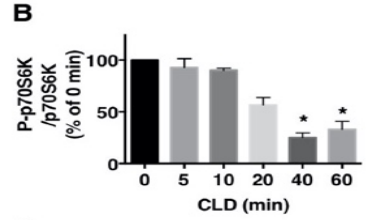

D

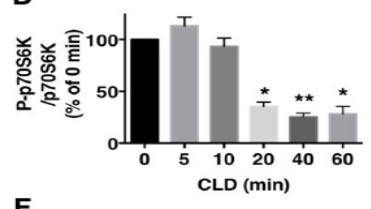

$\mathbf{F}$

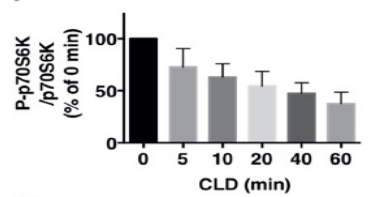

H

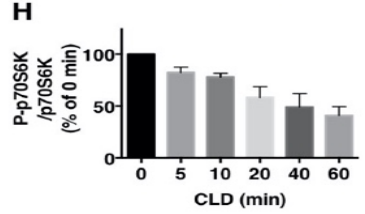

Figure 3. Time course effect of clindamycin on the phosphorylation of p70S6K in glioblastoma cell lines. Time course analysis of clindamycin (CLD) on p70S6K phosphorylation was determined in glioblastoma cell lines (A,C,E,G). Cells were assigned to the indicated times and cultured with CLD $(440 \mu \mathrm{M})$ and subjected to Western blotting. The levels of phosphorylation and total p70S6K were quantified after standardizing the ratio of phospho/total p70S6K (B,D,F,H). $\beta$-actin was used as the internal control level in all cases. Data are shown as the mean $\pm \mathrm{SE}$, similar results were obtained from three independent experiments. Each group was compared to the 0 min level to determine the statistical significance $\left({ }^{*} p<0.05\right.$ and ${ }^{* *} p<0.01$ vs. control culture: one-way ANOVA).

A IP: mTOR (N5D11)
Blot:
P-4EBP1 (Thr37/46)
4EBP1

D

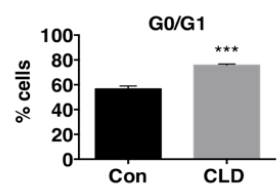

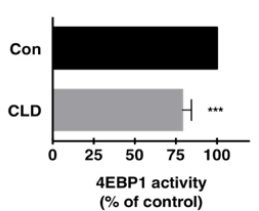

C

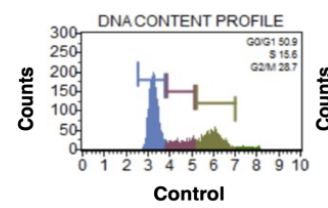

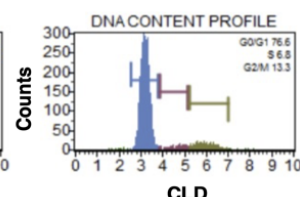

CLD

E
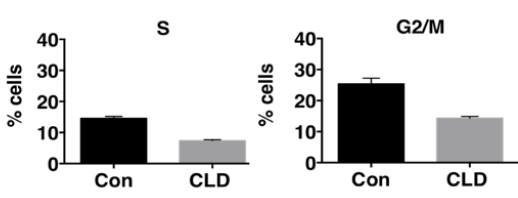

CLD CyclinD1 $\beta$-actin

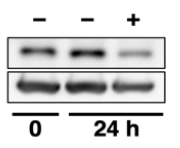

Figure 4. Direct effect of clindamycin on mTORC1 kinase activity and its involvement in the cell cycle progression at NGT41 cells. The in vitro kinase assay was examined in NGT41 cells. Cells were treated with a vehicle (control) or clindamycin (CLD) $440 \mu \mathrm{M}$ for $72 \mathrm{~h}$. Cell lysates were immunoprecipitated with the anti-mTOR (N5D11) antibody. The immunoprecipitates were added 4EBP1 as a substrate and were subjected to SDS-PAGE. mTORC1 activity was evaluated via Western blotting using anti-phospho 4EBP1 at the Thr37/46 antibody (A). The intensity of the immunoreactive band was quantified after standardizing the ratio of phospho/total 4EBP1 (B). Data are shown as the mean $\pm \mathrm{SE}$, where results were obtained from three independent experiments. ${ }^{* * *} p<0.001$ vs. control culture: $t$-test. NGT41 cells were treated with CLD $(440 \mu \mathrm{M})$ for $24 \mathrm{~h}$ and subjected to cell cycle analysis (C). Cells were classified into three phases: G0/G1, S, and G2/M (D). Data represent the percentage of cells in each phase, revealed as mean $\pm \mathrm{SE}$; similar results were obtained from three independent experiments. ${ }^{* *} p<0.005$ vs. control: $t$-test. The expression of cyclin D1 was analyzed via Western blotting (E). $\beta$-actin was used as the loading control. 


\subsection{Effect of Clindamycin on Cell Cycle Progression in GBM Cells}

To investigate the effects of CLD on the cell cycle progression, we treated NGT41 and T98G cells with $440 \mu \mathrm{M}$ CLD for $24 \mathrm{~h}$ and performed cell cycle analyses. The results showed that treatment with CLD induced G0/G1 phase arrest (Figure 4C). The percentage of NGT41 cells in the G0/G1 phase increased from 56.7\% to 75.8\% following CLD treatment (Figure 4D). In contrast, CLD treatment decreased the percentage of cells in the S-phase (from $14.5 \%$ to $7.3 \%$ ) and G2/M phase (from $25.4 \%$ to $14.3 \%$ ) of the cell cycle. Similar but more modest effects were observed in T98G cells (Figure S2A,B). Further, we examined the expression of the cell-cycle-related protein cyclin D1 via Western blotting. The results showed that treatment with CLD reduced the expression of cyclin D1 (Figure 4E).

\subsection{Effects of Clindamycin and Temozolomide Combined Treatment on Glioma Cell Viability}

Next, we investigated the effects of CLD and TMZ combination treatment on human glioblastoma cell lines. Each cell line was treated with a vehicle, CLD, TMZ, or CLD in combination with TMZ for $72 \mathrm{~h}$. In our preliminary experiments, we found that the minimum concentration of TMZ that was not totally cytotoxic and could reduce cell viability was $125 \mu \mathrm{M}$ (Figure S3). Co-treatment with CLD and TMZ significantly increased the cytotoxicity of MGMT-positive cell lines, T98G, and NGT41 (Figure 5A,B). The same additive effect of CLD was not observed in MGMT-negative cell lines, U251 and LN229 (Figure 5C,D). To elucidate the mechanism underlying the effect of combined CLD and TMZ treatment, we examined the MGMT protein level via Western blotting. The results showed that CLD suppressed MGMT in a dose-dependent manner in T98G and NGT41 cell lines (Figure 5E,F). MGMT mRNA expression was not affected by CLD in both cell lines (Figure S4).

\subsection{Synergistic Effects of Clindamycin and Temozolomide in a Subcutaneous Tumor Model}

Having confirmed the antitumor activity of the CLD and TMZ combined treatment in NGT41 cells, we next aimed to evaluate the combinatorial effects of these drugs in vivo using an orthotopic xenograft model. Nude mice bearing NGT41 xenografts were administered a vehicle, CLD, TMZ, or CLD in combination with TMZ daily for 10 days. The results showed that the combination treatment with CLD + TMZ significantly suppressed the tumor growth in vivo (Figure 6A). In contrast, CLD monotherapy had no effect on tumor growth in NGT41 xenografts. There were no adverse effects, such as weight loss or gastrointestinal dysfunction in animals that received the combination treatment (Figure S5). At the end of the treatment (day 10), the subcutaneous tumors were resected. Histopathological examination of these tumors showed that the combined treatment markedly decreased the number of MIB1-positive cells (Figure 6C). Moreover, Western blotting showed that the combined treatment suppressed the expression of MGMT in tumors, confirming its therapeutic potential during long-term treatment in vivo (Figure 6B). 
A

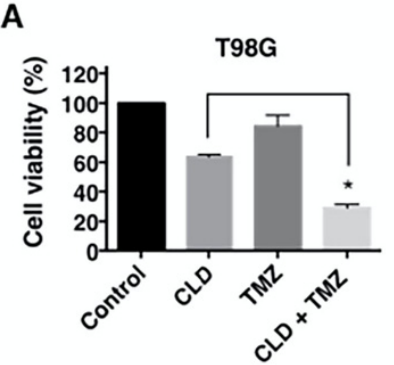

C

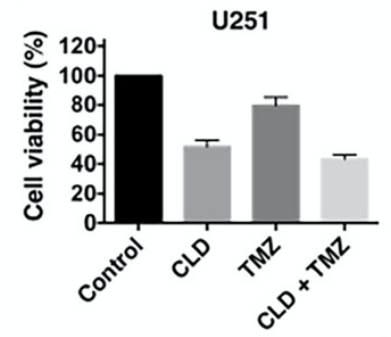

$E_{\text {T98G }}$

мамт

$\beta$-aotin

CLD $(\mu \mathrm{M}) \quad 0 \quad 110 \quad 220440$

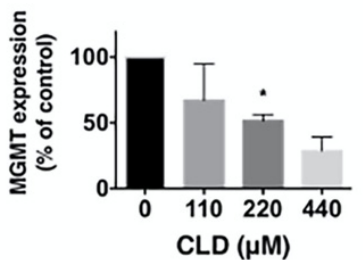

B

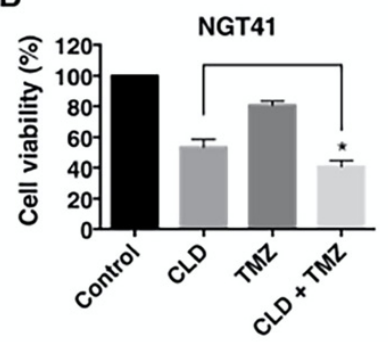

D

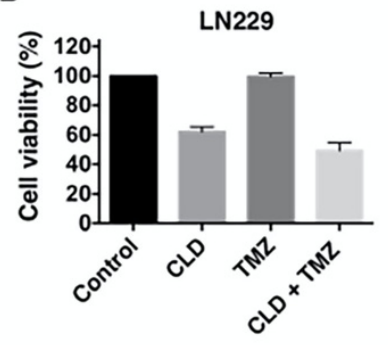

$F_{\text {NGT41 }}$

MGMT

$\beta$-aotin

CLD ( $\mu \mathrm{M}) \quad 0 \quad 110 \quad 220440$

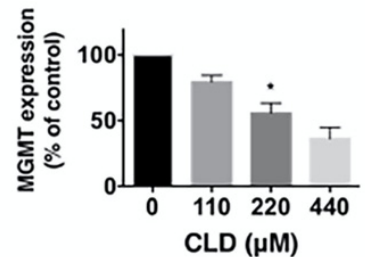

Figure 5. Effect of clindamycin and temozolomide combined treatment on glioblastoma cell viability. Combination effect of clindamycin (CLD) and temozolomide (TMZ) on glioblastoma cell viability (A-D). Cells were treated with a vehicle control, CLD $(440 \mu \mathrm{M})$, TMZ $(125 \mu \mathrm{M})$, or CLD $(440 \mu \mathrm{M})$ in combination with TMZ $(125 \mu \mathrm{M})$ for $72 \mathrm{~h}$ and subjected to a WST-1 cell viability assay. Data are presented as a percentage ratio to the vehicle control and are shown as the mean $\pm \mathrm{SE}$; similar results were representative of five independent experiments. The $p$-values were generated using a post hoc test for multiple comparisons, comparing CLD $+\mathrm{TMZ}$ with CLD alone in each cell line $\left({ }^{*} p<0.05\right.$ : one-way ANOVA). The dose response of CLD $(0,110,220$, or $440 \mu \mathrm{M})$ on the MGMT protein level was examined in T98G and NGT41 cell lines. After treatment for $72 \mathrm{~h}$, cell lysates were subjected to Western blotting using an anti-MGMT antibody $(\mathbf{E}, \mathbf{F}) . \beta$-actin was used as the loading control. 
A

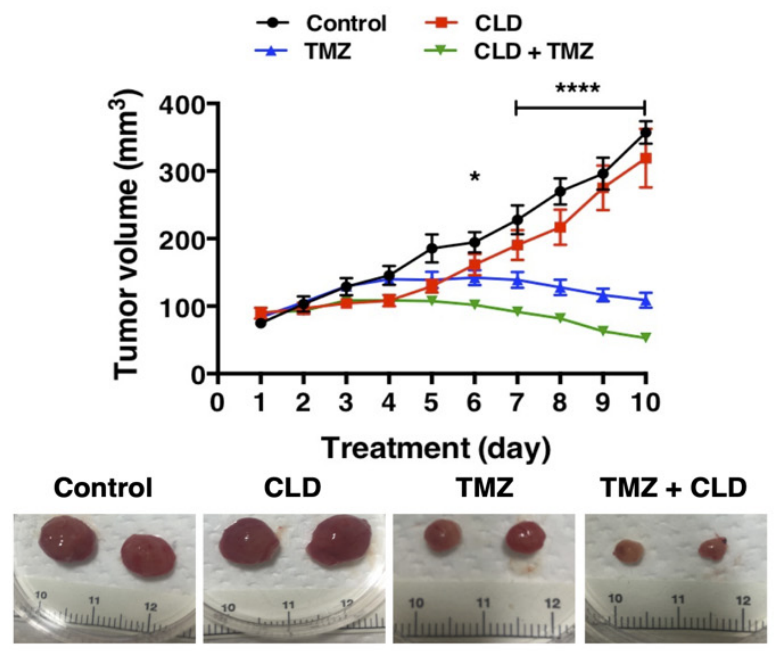

B

MGMT

$\beta$-actin

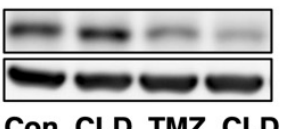

Con CLD TMZ CLD

C
Control
CLD
TMZ
TMZ + CLD

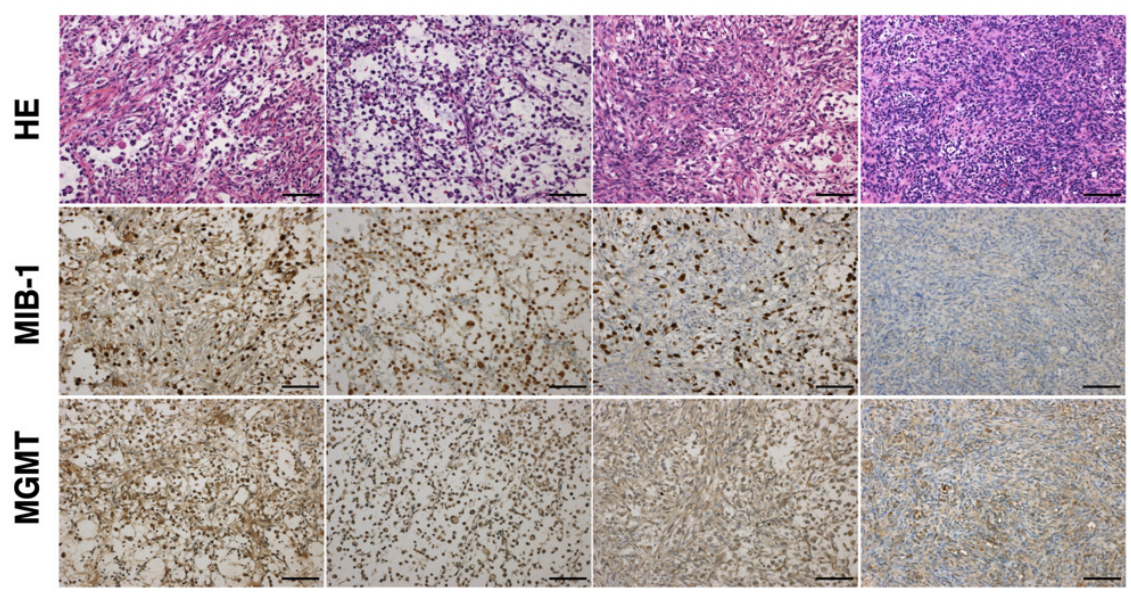

Figure 6. Synergistic effect of the clindamycin and temozolomide combined treatment in a subcutaneous tumor model. Efficacy of combined treatment for NGT41 subcutaneous xenograft model. Data represent the relationship between treatment days and tumor volume (A). Mice were administered a vehicle control, CLD (400 mg/ $\mathrm{kg})$, TMZ (5 mg/ kg), or CLD (400 mg/ $\mathrm{kg})$ in combination with TMZ (5 mg/kg) for 10 days. Data are shown as means \pm SE $(N=7)$. The $p$-values represent statistical comparisons between the CLD alone and combined treatment groups using Bonferroni multiple comparisons between independent samples $\left({ }^{*} p=0.0299\right.$ and ${ }^{* * *} p<0.0001$ vs. CLD alone: two-way ANOVA). Subcutaneous tumors were resected on day 10 and then homogenized. The lysates were subjected to Western blot analysis using an anti-MGMT antibody (B). The subcutaneous tumor resected from the NGT41 xenograft and its histological images are shown (C). Representative micrographs of subcutaneous tumors using HE and immunohistochemical staining with anti-MIB-1 and anti-MGMT antibodies on day 10. The results shown are representative of four independent experiments. Scale bar: $100 \mu \mathrm{m}$.

\section{Discussion}

GBM is one of the most aggressive tumors of the central nervous system (CNS). Despite multiple preclinical studies and the development of molecular targeted therapies, the overall survival of patients with GBM has not improved significantly. GBM has diverse 
genetic alterations and spatial and temporal heterogeneity, which have been implicated in chemotherapy resistance. In this study, we examined the anti-proliferative effects of the approved macrolides in human GBM cell lines. CLD markedly reduced the viability of GBM cells and inhibited p70S6K phosphorylation. Since PI3K-Akt-mTOR axis abnormalities are implicated in the etiology of GBM and other types of brain tumors [19,28-30], the activation of the mTOR pathway in the CNS is a subject of intense research. mTOR is a serine/threonine kinase that forms mTOR complex (mTORC) 1 and 2, depending on the binding partners. mTORC1 is activated by amino acids and growth factors and plays a central role in cell growth and proliferation. Upon mTORC1 activation, the phosphorylation of its substrates, such as p70S6K and eukaryotic initiation factor 4E binding protein $(4 \mathrm{EBP})$, is increased. Thus, the phosphorylation ratio of these molecules is often used as an index of mTORC1 activity [31,32]. Consistent with our hypothesis, CLD attenuated the phosphorylation of p70S6K and S6 ribosomal protein in a dose-dependent manner. In vitro kinase assays revealed that CLD directly affected the mTORC1 activity. These results suggested that CLD inhibited the mTOR signaling that is required for GBM growth.

To delineate the mechanism underlying the anti-proliferative effect of CLD, we performed cell cycle analysis. Treatment with CLD increased the percentage of cells in the G0/G1 phase and decreased the percentage of cells in the S and G2/M phases, suggesting that CLD induced G0/G1 arrest. There are several reports showing that mTOR inhibitors suppress cell proliferation. Rapamycin treatment or mTOR depletion induces cell cycle arrest in the G1/S phase and leads to a decrease in nucleolar size [33]. Rapamycin and its derivatives, namely, CCI-779 and RAD001, inhibit the phosphorylation of p70S6K and 4EBP1, leading to G1-phase cell cycle arrest [34]. It might be possible that aberrant PI3KAkt-mTOR signaling contributes to proliferation in gliomagenesis, and the cytotoxic effects of CLD are mediated via mTOR.

Interestingly, our results showed that in MGMT-positive cell lines, namely, T98G and NGT41, the antitumor effect of CLD was significantly enhanced by TMZ co-treatment. Moreover, CLD suppressed the levels of MGMT protein in these cells, and long-term treatment with CLD and TMZ decreased the MGMT in xenografts. Furthermore, CLD and TMZ combination therapy markedly reduced the number of MIB1-positive cells within the tumor. This suggests that CLD suppresses MGMT protein expression and enhances the antitumor activity of TMZ. However, the long-term administration of CLD alone failed to suppress tumor growth. It was reported that after mTOR inhibition, pathway signaling plasticity with redundant signal input and reactivation by a feedback loop occurs [35]. Our results are consistent with the previous report. Therefore, combinatorial approaches for manipulating the PI3K-Akt axis and inhibiting the mTOR kinase to inactivate the feedback loop have been proposed [36]. Preclinical studies demonstrated the efficacy of XL765, a PI3K/mTOR dual inhibitor, in combination with TMZ against GBM xenografts [37-39]. Results of the present study suggested that CLD was effective in combination with TMZ.

In TMZ-based chemotherapy, where DNA mismatch and subsequent apoptosis occurs, resistance has been associated with MGMT expression [40]. Dose-dense TMZ or TMZ and interferon combination therapy was proposed as a potential treatment strategy to deplete MGMT, although all large clinical trials attempting to exploit this have failed [41,42]. We observed the effectiveness of CLD and TMZ combination in MGMT-positive cell lines. CLD may sensitize these cells to TMZ by reducing the MGMT protein level. CLD did not affect the MGMT mRNA, thus CLD suppressed MGMT protein during the translation processes or at the protein degradation levels. Since mTORC1 controls translation and autophagy [43], CLD decreases MGMT protein possibly through these mechanisms.

CLD exerts an antibacterial effect by binding to the $50 \mathrm{~S}$ ribosomal subunit of susceptible bacteria, causing a reduction in the cessation of protein synthesis; however, its effects on eukaryotes are not well understood. Thus, the exact molecular mechanism by which CLD reduces MGMT protein remains unknown and further investigation is warranted.

We investigated the effect of CLD on NGT41 cell proliferation. NGT41 is a cell line that was established from an epithelioid GBM harboring the BRAF V600E mutation. 
We previously confirmed the NGT41 tumor cell response to combination therapy with dabrafenib and trametinib in vitro and in vivo [20]. mTOR pathway activation is thought to be one of the main mechanisms of resistance in BRAF V600E-mutant brain tumors following targeted treatment [44-46]. This further supports the notion of integration of the Ras-ERK and PI3K-mTORC1 pathways and the mechanisms of crosstalk include negative feedback loops, cross-inhibition, cross-activation, and pathway convergence on substrates [47]. mTORC1 is the center of the crosstalk, as it receives several inputs from both Ras-ERK and PI3K signaling pathways. Our findings suggest that mTOR inhibition by CLD is effective in treating BRAF V600E mutant glioblastomas.

Our cell culture experiments revealed that treatment with 110-440 $\mu \mathrm{M}$ (i.e., 50-200 $\mu \mathrm{g} / \mathrm{mL}$ ) CLD significantly attenuated the phosphorylation of p70S6K and S6K in GBM cell lines. However, in our animal studies, we did not determine the concentration of CLD or its metabolites in the serum following CLD injection. It is important to consider whether these ranges of CLD can be achieved in the CNS. In adult humans, the peak concentration of CLD in the plasma following $900 \mathrm{mg}$ intravenous injection of CLD phosphate is approximately $14.1 \mu \mathrm{g} / \mathrm{mL}$. For severe infections, intravenous administration of $1200-4800 \mathrm{mg}$ per day has been used (Pfizer Inc., medical information; CLEOCIN phosphate injection, http: / / www.pfizer.com, accessed on 1 December 2021) Thus, the CLD dose used in our culture experiments was higher than that used in a clinical setting. Imaoka et al. reported that in adult rats, a single intravenous injection of CLD $(30 \mathrm{mg} / \mathrm{kg})$ resulted in a peak concentration of $48 \mu \mathrm{g} / \mathrm{mL}$ in the lungs; however, the distribution of CLD in the brain was found to be relatively lower [48]. CLD cannot cross the blood-brain barrier, and it is known that CLD does not reach the cerebrospinal fluid. In our experiments, repeated and high-dose $(400 \mathrm{mg} / \mathrm{kg})$ administration had no adverse effect, such as significant weight loss on the mice (Figure S5). In a mouse endotoxic shock model, pretreatment with CLD (440 mg/kg, intraperitoneal) suppressed the release of inflammatory cytokines [49]. The effective concentration of CLD used in the present study appeared to be tolerable in mice. Further research is required to understand how CLD and its combination treatment have a local impact on CNS regarding the proliferation and activation of GBM cell metabolism. To improve drug distribution to the brain, methods such as convection-enhanced delivery [50,51] and intranasal delivery [52,53] of nanoliposomal drugs, use of nanoparticles [54], and blood-brain barrier disruption by focused ultrasound [55] were investigated and could be applied to CNS delivery of CLD.

Drug repositioning, or identifying and developing new uses of existing drugs, is a promising method used in the pharmaceutical industry to reduce the cost of developing new therapeutical drugs [56]. Our group [25], as well as others [57], performed drug repositioning to identify candidate drugs for use against glioblastomas and other brain tumors [58]. Specifically, antibiotics have gained considerable interest in drug repurposing for cancer therapy [59]. In the present study, through a simple screening of four macrolides, we found that the commonly used CLD exerts cytotoxic effects on GBM cell lines and is a candidate for drug repositioning.

\section{Conclusions}

In conclusion, in GBM cell lines, CLD inhibited the mTOR signaling, which is frequently dysregulated in cancers. Moreover, CLD enhanced the susceptibility of GBM cells toward TMZ-based therapy, which is presently a standard treatment for GBM. We speculate that a CLD and TMZ combination therapy prevented the development of drug resistance by reducing MGMT through mTOR signal downregulation. CLD is an exciting candidate drug for repositioning, and combined CLD and TMZ therapy is a potentially new and useful strategy for targeting glioblastomas. 
Supplementary Materials: The following are available online at https:/ /www.mdpi.com/article/10 .3390 / cancers14030770/s1, Figure S1: Effect of approved macrolide antibiotics on the cell proliferation of U251 and T98G cells, Figure S2: Effect of clindamycin on the cell cycle progression in T98G cells, Figure S3: Dose response of temozolomide on cell proliferation in glioblastoma cell lines, Figure S4: Analysis of MGMT mRNA expression, Figure S5: Measurement of mice weights during the treatment period with clindamycin and temozolomide, Figure S6: Original Western blot.

Author Contributions: T.E., M.O. (Masayasu Okada), N.T. and M.N. conceived and designed the experiments and coordinated the work presented in this manuscript. T.E., M.O. (Masayasu Okada), Y.K., J.O. and N.T. performed the experiments. T.E., M.N., M.O. (Masayasu Okada), R.O., Y.T., J.W., N.T., H.A. and M.O. (Makoto Oishi) interpreted the results. T.E. drafted the manuscript. Y.F. supervised the study. All authors read and agreed to the published version of the manuscript.

Funding: This work was supported by KAKENHI grants from the Japanese Society for the Promotion of Science to T.E. (17K08304, 20K07194), M.N. (17K16632, 19K09476), and M.O. (Masayasu Okada) (17K17739, 20K17955).

Institutional Review Board Statement: The study was conducted according to the guidelines of the Declaration of Helsinki and approved by the Institutional Review Board of Niigata University (Approval \# 2015-2583, approval date 25 July 2016, extension granted 31 March 2020).

Informed Consent Statement: Written informed consent was obtained from patients or patients' families whose tumor we derived the cell lines from.

Data Availability Statement: The datasets analyzed during the current study are available from the corresponding author upon request.

Acknowledgments: We would like to thank Kenji Oyachi, histopathology core facility, Niigata University Faculty of Medicine, for technical support regarding the excision of pathological specimen tissue.

Conflicts of Interest: The authors declare no conflict of interest.

\section{References}

1. Louis, D.N.; Perry, A.; Reifenberger, G.; von Deimling, A.; Figarella-Branger, D.; Cavenee, W.K.; Ohgaki, H.; Wiestler, O.D.; Kleihues, P.; Ellison, D.W. The 2016 World Health Organization Classification of Tumors of the Central Nervous System: A summary. Acta Neuropathol. 2016, 131, 803-820. [CrossRef] [PubMed]

2. Stupp, R.; Mason, W.P.; van den Bent, M.J.; Weller, M.; Fisher, B.; Taphoorn, M.J.; Belanger, K.; Brandes, A.A.; Marosi, C.; Bogdahn, U.; et al. Radiotherapy plus concomitant and adjuvant temozolomide for glioblastoma. N. Engl. J. Med. 2005, 352, 987-996. [CrossRef] [PubMed]

3. Stupp, R.; Hegi, M.E.; Mason, W.P.; van den Bent, M.J.; Taphoorn, M.J.; Janzer, R.C.; Ludwin, S.K.; Allgeier, A.; Fisher, B.; Belanger, K.; et al. Effects of radiotherapy with concomitant and adjuvant temozolomide versus radiotherapy alone on survival in glioblastoma in a randomised phase III study: 5-year analysis of the EORTC-NCIC trial. Lancet Oncol. 2009, 10, 459-466. [CrossRef]

4. Hegi, M.E.; Diserens, A.C.; Gorlia, T.; Hamou, M.F.; Nicolas, T.; Weller, M.; Kros, J.M.; Hainfellner, J.A.; Mason, W.; Mariani, L.; et al. MGMT Gene Silencing and Benefit from Temozolomide in Glioblastoma. N. Engl. J. Med. 2005, 352, 997-1003. [CrossRef] [PubMed]

5. Nishikawa, R.; Ji, X.D.; Harmon, R.C.; Lazar, C.S.; Gill, G.N.; Cavenee, W.K.; Huang, H.J. A mutant epidermal growth factor receptor common in human gliomaconfersenhancedtumorigenicity. Proc. Natl. Acad. Sci. USA 1994, 91, 7727-7731. [CrossRef] [PubMed]

6. Padfield, E.; Ellis, H.P.; Kurian, K.M. Current Therapeutic Advances Targeting EGFR and EGFRvIII in Glioblastoma. Front. Oncol. 2015, 5, 5. [CrossRef] [PubMed]

7. Sanson, M.; Marie, Y.; Paris, S.; Idbaih, A.; Laffaire, J.; Ducray, F.; El Hallani, S.; Boisselier, B.; Mokhtari, K.; Hoang-Xuan, K.; et al. Isocitrate Dehydrogenase 1 Codon 132 Mutation Is an Important Prognostic Biomarker in Gliomas. J. Clin. Oncol. 2009, 27, 4150-4154. [CrossRef] [PubMed]

8. Ohgaki, H.; Dessen, P.; Jourde, B.; Horstmann, S.; Nishikawa, T.; Di Patre, P.; Burkhard, C.; Schüler, D.; Probst-Hensch, N.; Maiorka, P.; et al. Genetic Pathways to Glioblastoma. Cancer Res. 2004, 64, 6892-6899. [CrossRef]

9. The Cancer Genome Atlas Research Network. Comprehensive genomic characterization defines human glioblastoma genes and core pathways. Nature 2008, 455, 1061-1068. [CrossRef]

10. Knobbe, C.B.; Reifenberger, G. Genetic Alterations and Aberrant Expression of Genes Related to the Phosphatidyl-Inositol-3'Kinase/Protein Kinase B (Akt) Signal TransductionPathway in Glioblastomas. Brain Pathol. 2003, 13, 507-518. [CrossRef] 
11. Brennan, C.W.; Verhaak, R.G.; McKenna, A.; Campos, B.; Noushmehr, H.; Salama, S.R.; Zheng, S.; Chakravarty, D.; Sanborn, J.Z.; Berman, S.H.; et al. The somatic genomic landscape of glioblastoma. Cell 2013, 155, 462-477. [CrossRef] [PubMed]

12. Zarogoulidis, P.; Papanas, N.; Kioumis, I.; Chatzaki, E.; Maltezos, E.; Zarogoulidis, K. Macrolides: From in vitro anti-inflammatory and immunomodulatory properties to clinical practice in respiratory diseases. Eur. J. Clin. Pharmacol. 2012, 68, 479-503. [CrossRef] [PubMed]

13. Kanoh, S.; Rubin, B. Mechanisms of action and clinical application of macrolides as immunomodulatory medications. Clin. Microbiol. Rev. 2010, 23, 590-615. [CrossRef] [PubMed]

14. Shinkai, M.; Henke, M.O.; Rubin, B.K. Macrolide antibiotics as immunomodulatory medications: Proposed mechanisms of action. Pharmacol. Ther. 2008, 117, 393-405. [CrossRef] [PubMed]

15. Kudoh, S.; Azuma, A.; Yamamoto, M.; Izumi, T.; Ando, M. Improvement of survival in patients with diffuse panbronchiolitis treated with low-dose erythromycin. Am. J. Respir. Crit. Care Med. 1998, 157, 1829-1832. [CrossRef]

16. Ratzinger, F.; Haslacher, H.; Poeppl, W.; Hoermann, G.; Kovarik, J.J.; Jutz, S.; Steinberger, P.; Burgmann, H.; Pickl, W.F.; Schmetterer, K.G. Azithromycin suppresses CD4(+) T-cell activation by direct modulation of mTOR activity. Sci. Rep. 2014, 4, 7438. [CrossRef]

17. Akhavan, D.; Cloughesy, T.F.; Mischel, P.S. mTOR signaling in glioblastoma: Lessons learned from bench to bedside. Neuro Oncol. 2010, 12, 882-889. [CrossRef]

18. Furnari, F.B.; Fenton, T.; Bachoo, R.M.; Mukasa, A.; Stommel, J.M.; Stegh, A.; Hahn, W.C.; Ligon, K.L.; Louis, D.N.; Brennan, C.; et al. Malignant astrocytic glioma: Genetics, biology, and paths to treatment. Genes Dev. 2007, 21, 2683-2710. [CrossRef]

19. Laplante, M.; Sabatini, D.M. mTOR signaling in growth control and disease. Cell 2012, 149, 274-293. [CrossRef]

20. Kanemaru, Y.; Natsumeda, M.; Okada, M.; Saito, R.; Kobayashi, D.; Eda, T.; Watanabe, J.; Saito, S.; Tsukamoto, Y.; Oishi, M.; et al. Dramatic response of BRAF V600E-mutant epithelioid glioblastoma to combination therapy with BRAF and MEK inhibitor: Establishment and xenograft of a cell line to predict clinical efficacy. Acta Neuropathol. Commun. 2019, 7, 119. [CrossRef]

21. Aoki, H.; Takada, Y.; Kondo, S.; Sawaya, R.; Aggarwal, B.B.; Kondo, Y. Evidence that curcumin suppresses the growth of malignant gliomas in vitro and in vivo through induction of autophagy: Role of Akt and extracellular signal-regulated kinase signaling pathways. Mol. Pharmacol. 2007, 72, 29-39. [CrossRef] [PubMed]

22. Nishiuma, T.; Hara, K.; Tsujishita, Y.; Kaneko, K.; Shii, K.; Yonezawa, K. Characterization of the Phosphoproteins and Protein Kinase Activity in mTOR Immunoprecipitates. Biochem. Biophys. Res. Commun. 1998, 252, 440-444. [CrossRef] [PubMed]

23. Takei, N.; Kawamura, M.; Hara, K.; Yonezawa, K.; Nawa, H. Brain-derived neurotrophic factor enhances neuronal translation by activating multiple initiation processes: Comparison with the effects of insulin. J. Biol. Chem. 2001, 276, 42818-42825. [CrossRef] [PubMed]

24. Natsumeda, M.; Maitani, K.; Liu, Y.; Miyahara, H.; Kaur, H.; Chu, Q.; Zhang, H.; Kahlert, U.D.; Eberhart, C.G. Targeting Notch Signaling and Autophagy Increases Cytotoxicity in Glioblastoma Neurospheres. Brain Pathol. 2016, 26, 713-723. [CrossRef] [PubMed]

25. Tsukamoto, Y.; Ohtsu, N.; Echizenya, S.; Otsuguro, S.; Ogura, R.; Natsumeda, M.; Isogawa, M.; Aoki, H.; Ichikawa, S.; Sakaitani, M.; et al. Chemical Screening Identifies EUrd as a Novel Inhibitor Against Temozolomide-Resistant Glioblastoma-Initiating Cells. Stem Cells 2016, 34, 2016-2025. [CrossRef]

26. Okada, M.; Kawagoe, Y.; Sato, Y.; Nozumi, M.; Ishikawa, Y.; Tamada, A.; Yamazaki, H.; Sekino, Y.; Kanemura, Y.; Shinmyo, Y.; et al. Phosphorylation of GAP-43 T172 is a molecular marker of growing axons in a wide range of mammals including primates. Mol. Brain 2021, 14, 66. [CrossRef]

27. Ogura, R.; Tsukamoto, Y.; Natsumeda, M.; Isogawa, M.; Aoki, H.; Kobayashi, T.; Yoshida, S.; Okamoto, K.; Takahashi, H.; Fujii, Y.; et al. Immunohistochemical profiles of IDH1, MGMT and P53: Practical significance for prognostication of patients with diffuse gliomas. Neuropathology 2015, 35, 324-335. [CrossRef]

28. Abedalthagafi, M.; Bi, W.L.; Aizer, A.A.; Merrill, P.H.; Brewster, R.; Agarwalla, P.K.; Listewnik, M.L.; Dias-Santagata, D.; Thorner, A.R.; Van Hummelen, P.; et al. Oncogenic PI3K mutations are as common as AKT1 and SMO mutations in meningioma. Neuro Oncol. 2016, 18, 649-655. [CrossRef] [PubMed]

29. Miyahara, H.; Yadavilli, S.; Natsumeda, M.; Rubens, J.A.; Rodgers, L.; Kambhampati, M.; Taylor, I.C.; Kaur, H.; Asnaghi, L.; Eberhart, C.G.; et al. The dual mTOR kinase inhibitor TAK228 inhibits tumorigenicity and enhances radiosensitization in diffuse intrinsic pontine glioma. Cancer Lett. 2017, 400, 110-116. [CrossRef]

30. Gini, B.; Zanca, C.; Guo, D.; Matsutani, T.; Masui, K.; Ikegami, S.; Yang, H.; Nathanson, D.; Villa, G.R.; Shackelford, D.; et al. The mTOR kinase inhibitors, CC214-1 and CC214-2, preferentially block the growth of EGFRvIII-activated glioblastomas. Clin. Cancer Res. 2013, 19, 5722-5732. [CrossRef]

31. Hara, K.; Yonezawa, K.; Weng, Q.P.; Kozlowski, M.T.; Belham, C.; Avruch, J. Amino acid sufficiency and mTOR regulate p70 S6 kinase and eIF-4E BP1 through a common effector mechanism. J. Biol. Chem. 1998, 273, 14484-14494. [CrossRef] [PubMed]

32. Takei, N.; Nawa, H. mTOR signaling and its roles in normal and abnormal brain development. Front. Mol. Neurosci. 2014, 7, 28. [CrossRef] [PubMed]

33. Mayer, C.; Grummt, I. Ribosome biogenesis and cell growth: mTOR coordinates transcription by all three classes of nuclear RNA polymerases. Oncogene 2006, 25, 6384-6391. [CrossRef] [PubMed]

34. Takeuchi, H.; Kondo, Y.; Fujiwara, K.; Kanzawa, T.; Aoki, H.; Mills, G.B.; Kondo, S. Synergistic augmentation of rapamycininduced autophagy in malignant glioma cells by phosphatidylinositol 3-kinase/protein kinase B inhibitors. Cancer Res. 2005, 65, 3336-3346. [CrossRef] 
35. O'Reilly, K.E.; Rojo, F.; She, Q.-B.; Solit, D.; Mills, G.B.; Smith, D.; Lane, H.; Hofmann, F.; Hicklin, D.J.; Ludwig, D.L.; et al. mTOR Inhibition Induces Upstream Receptor Tyrosine Kinase Signaling and Activates Akt. Cancer Res. 2006, 66, 1500-1508. [CrossRef]

36. Janku, F.; Yap, T.A.; Meric-Bernstam, F. Targeting the PI3K pathway in cancer: Are we making headway? Nat. Rev. Clin. Oncol. 2018, 15, 273-291. [CrossRef]

37. Liu, T.J.; Koul, D.; LaFortune, T.; Tiao, N.; Shen, R.J.; Maira, S.M.; Garcia-Echevrria, C.; Yung, W.K. NVP-BEZ235, a novel dual phosphatidylinositol 3-kinase/mammalian target of rapamycin inhibitor, elicits multifaceted antitumor activities in human gliomas. Mol. Cancer Ther. 2009, 8, 2204-2210. [CrossRef] [PubMed]

38. Prasad, G.; Sottero, T.; Yang, X.; Mueller, S.; James, C.D.; Weiss, W.A.; Polley, M.Y.; Ozawa, T.; Berger, M.S.; Aftab, D.T.; et al. Inhibition of PI3K/mTOR pathways in glioblastoma and implications for combination therapy with temozolomide. Neuro Oncol. 2011, 13, 384-392. [CrossRef]

39. von Achenbach, C.; Weller, M.; Kaulich, K.; Gramatzki, D.; Zacher, A.; Fabbro, D.; Reifenberger, G.; Szabo, E. Synergistic growth inhibition mediated by dual PI3K/mTOR pathway targeting and genetic or direct pharmacological AKT inhibition in human glioblastoma models. J. Neurochem. 2020, 153, 510-524. [CrossRef]

40. Pegg, A.E. Repair of O6-alkylguanine by alkyltransferases. Mutat. Res. 2000, 462, 83-100. [CrossRef]

41. Gilbert, M.R.; Wang, M.; Aldape, K.D.; Stupp, R.; Hegi, M.E.; Jaeckle, K.A.; Armstrong, T.S.; Wefel, J.S.; Won, M.; Blumenthal, D.T.; et al. Dose-dense temozolomide for newly diagnosed glioblastoma: A randomized phase III clinical trial. J. Clin. Oncol. 2013, 31, 4085-4091. [CrossRef] [PubMed]

42. Wakabayashi, T.; Natsume, A.; Mizusawa, J.; Katayama, H.; Fukuda, H.; Sumi, M.; Nishikawa, R.; Narita, Y.; Muragaki, Y.; Maruyama, T.; et al. JCOG0911 INTEGRA study: A randomized screening phase II trial of interferonbeta plus temozolomide in comparison with temozolomide alone for newly diagnosed glioblastoma. J. Neurooncol. 2018, 138, 627-636. [CrossRef] [PubMed]

43. Spriggs, K.A.; Bushell, M.; Willis, A.E. Translational regulation of gene expression during conditions of cell stress. Mol. Cell 2010, 40, 228-237. [CrossRef] [PubMed]

44. Sievert, A.J.; Lang, S.S.; Boucher, K.L.; Madsen, P.J.; Slaunwhite, E.; Choudhari, N.; Kellet, M.; Storm, P.B.; Resnick, A.C. Paradoxical activation and RAF inhibitor resistance of BRAF protein kinase fusions characterizing pediatric astrocytomas. Proc. Natl. Acad. Sci. USA 2013, 110, 8750. [CrossRef]

45. Arnold, A.; Yuan, M.; Price, A.; Harris, L.; Eberhart, C.G.; Raabe, E.H. Synergistic activity of mTORC1/2 kinase and MEK inhibitors suppresses pediatric low-grade glioma tumorigenicity and vascularity. Neuro Oncol. 2020, 22, 563-574. [CrossRef]

46. Conciatori, F.; Ciuffreda, L.; Bazzichetto, C.; Falcone, I.; Pilotto, S.; Bria, E.; Cognetti, F.; Milella, M. mTOR Cross-Talk in Cancer and Potential for Combination Therapy. Cancers 2018, 10, 23. [CrossRef]

47. Mendoza, M.C.; Er, E.E.; Blenis, J. The Ras-ERK and PI3K-mTOR pathways: Cross-talk and compensation. Trends Biochem. Sci. 2011, 36, 320-328. [CrossRef]

48. Imaoka, M.; Uzuka, Y.; Noguchi, Y.; Watanabe, K.; Matsumoto, K. Basic and clinical studies on clindamycin for intravenous injection. Jpn. J. Antibiot. 1977, 30, 51-58.

49. Hirata, N.; Hiramatsu, K.; Kishi, K.; Yamasaki, T.; Ichimiya, T.; Nasu, M. Pretreatment of mice with clindamycin improves survival of endotoxic shock by modulating the release of inflammatory cytokines. Antimicrob. Agents Chemother. 2001, 45, 2638-2642 [CrossRef]

50. Yoshimura, J.; Siu, I.M.; Thomale, U.W.; Jallo, G.I. The effects of temozolomide delivered by prolonged intracerebral microinfusion against the rat brainstem GBM allograft model. Childs Nerv. Syst. 2012, 28, 707-713. [CrossRef]

51. Saito, R.; Sonoda, Y.; Kumabe, T.; Nagamatsu, K.; Watanabe, M.; Tominaga, T. Regression of recurrent glioblastoma infiltrating the brainstem after convection-enhanced delivery of nimustine hydrochloride. J. Neurosurg. Pediatr. 2011, 7, 522-526. [CrossRef] [PubMed]

52. Hashizume, R.; Ozawa, T.; Gryaznov, S.M.; Bollen, A.W.; Lamborn, K.R.; Frey, W.H., II; Deen, D.F. New therapeutic approach for brain tumors: Intranasal delivery of telomerase inhibitor GRN163. Neuro Oncol. 2008, 10, 112-120. [CrossRef] [PubMed]

53. Louis, N.; Liu, S.; He, X.; Drummond, D.C.; Noble, C.O.; Goldman, S.; Mueller, S.; Bankiewicz, K.; Gupta, N.; Hashizume, R. New therapeutic approaches for brainstem tumors: A comparison of delivery routes using nanoliposomal irinotecan in an animal model. J. Neurooncol. 2018, 136, 475-484. [CrossRef]

54. Lim, K.J.; Bisht, S.; Bar, E.E.; Maitra, A.; Eberhart, C.G. A polymeric nanoparticle formulation of curcumin inhibits growth, clonogenicity and stem-like fraction in malignant brain tumors. Cancer Biol. Ther. 2011, 11, 464-473. [CrossRef] [PubMed]

55. Wei, K.C.; Chu, P.C.; Wang, H.Y.; Huang, C.Y.; Chen, P.Y.; Tsai, H.C.; Lu, Y.J.; Lee, P.Y.; Tseng, I.C.; Feng, L.Y.; et al. Focused ultrasound-induced blood-brain barrier opening to enhance temozolomide delivery for glioblastoma treatment: A preclinical study. PLoS ONE 2013, 8, e58995. [CrossRef] [PubMed]

56. Ashburn, T.T.; Thor, K.B. Drug repositioning: Identifying and developing new uses for existing drugs. Nat. Rev. Drug Discov. 2004, 3, 673-683. [CrossRef]

57. Dong, Y.; Furuta, T.; Sabit, H.; Kitabayashi, T.; Jiapaer, S.; Kobayashi, M.; Ino, Y.; Todo, T.; Teng, L.; Hirao, A.; et al. Identification of antipsychotic drug fluspirilene as a potential anti-glioma stem cell drug. Oncotarget 2017, 8, 111728-111741. [CrossRef] [PubMed]

58. Grasso, C.S.; Tang, Y.; Truffaux, N.; Berlow, N.E.; Liu, L.; Debily, M.A.; Quist, M.J.; Davis, L.E.; Huang, E.C.; Woo, P.J.; et al Functionally defined therapeutic targets in diffuse intrinsic pontine glioma. Nat. Med. 2015, 21, 555-559. [CrossRef]

59. Pfab, C.; Schnobrich, L.; Eldnasoury, S.; Gessner, A.; El-Najjar, N. Repurposing of Antimicrobial Agents for Cancer Therapy: What Do We Know? Cancers 2021, 13, 3193. [CrossRef] [PubMed] 